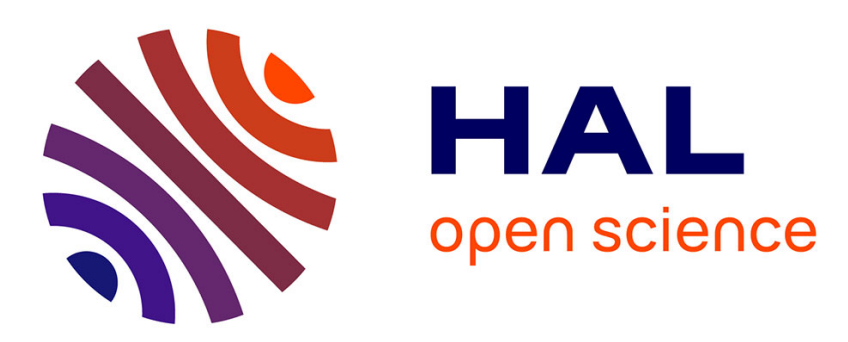

\title{
Fluvial and lacustrine activity on layered deposits in Melas Chasma, Valles Marineris, Mars
}

C. Quantin, P. Allemand, N. Mangold, G. Dromart, Christophe Delacourt

\section{To cite this version:}

C. Quantin, P. Allemand, N. Mangold, G. Dromart, Christophe Delacourt. Fluvial and lacustrine activity on layered deposits in Melas Chasma, Valles Marineris, Mars. Journal of Geophysical Research. Planets, 2005, 110 (E12), pp.E12. 10.1029/2005JE002440 . hal-00379885

\section{HAL Id: hal-00379885 \\ https://hal.science/hal-00379885}

Submitted on 13 Feb 2021

HAL is a multi-disciplinary open access archive for the deposit and dissemination of scientific research documents, whether they are published or not. The documents may come from teaching and research institutions in France or abroad, or from public or private research centers.
L'archive ouverte pluridisciplinaire HAL, est destinée au dépôt et à la diffusion de documents scientifiques de niveau recherche, publiés ou non, émanant des établissements d'enseignement et de recherche français ou étrangers, des laboratoires publics ou privés. 


\title{
Fluvial and lacustrine activity on layered deposits in Melas Chasma, Valles Marineris, Mars
}

\author{
C. Quantin and P. Allemand \\ Laboratoire Sciences de la Terre, UMR 5570, CNRS Université Claude Bernard Lyon 1, Lyon, France
}

\author{
N. Mangold \\ OrsayTerre, Université Paris-Sud, Orsay, France \\ G. Dromart and C. Delacourt \\ Laboratoire Sciences de la Terre, UMR 5570, CNRS Université Claude Bernard Lyon 1, Lyon, France
}

Received 1 April 2005; revised 8 July 2005; accepted 14 July 2005; published 13 October 2005.

[1] Valley networks on Mars are the most obvious features attesting that different geologic processes and possibly climatic conditions existed in the past. THEMIS images reveal valley networks within Melas Chasma, in Valles Marineris, a Hesperian-age canyon system. The valley networks in Melas Chasma are dense and highly organized, and the heads of the valleys are scattered at different elevations. All these features suggest that the networks were fed by precipitation. The morphological details reveal inner channels on some valley floors, attesting that water flowed within these valleys. On the DEM, the valleys flow into a completely enclosed depression. The edge of this feature follows a MOLA contour line, and the depression shows many sedimentary morphologies suggesting lacustrine environment. These landforms are located on remnants of layered deposits possibly composed of sulfate layers suggesting that fluvial activity could have contributed to the erosion of the layered terrains in Valles Marineris. Collectively, the features in Melas Chasma are a maximum of Hesperian in age. These results suggest that warm, wet environmental conditions on Mars persisted through the Hesperian and were present during the formation of Valles Marineris. The evidence for a paleolake in Melas Chasma attests to adequate environmental conditions for life development through the Hesperian period.

Citation: Quantin, C., P. Allemand, N. Mangold, G. Dromart, and C. Delacourt (2005), Fluvial and lacustrine activity on layered deposits in Melas Chasma, Valles Marineris, Mars, J. Geophys. Res., 110, E12S19, doi:10.1029/2005JE002440.

\section{Introduction}

[2] Valley networks on Mars are the most obvious features attesting that different geologic processes and possibly climatic conditions existed in the past. The networks, which are located primarily on Noachian terrains [Craddock and Howard, 2002], have been suggested to be indicative of precipitation and surface runoff [Masursky, 1973, Masursky et al., 1977; Craddock and Maxwell, 1993; Squyres and Kasting, 1994; Carr, 1995, 1999; Pollack et al., 1987; Baker, 2001; Craddock and Howard, 2002]. Conditions necessary to support rainfall and runoff would imply that the atmosphere was much warmer and denser than today, possibly sustained by an efficient greenhouse effect [Squyres and Kasting, 1994; Haberle, 1998].

[3] Martian valley networks are markedly different than their terrestrial counterparts [Aharonson et al., 2002; Stepinski et al., 2004]. Valley network drainage density (i.e., the ratio between the cumulative length of the valleys

Copyright 2005 by the American Geophysical Union. 0148-0227/05/2005JE002440 and the total drainage area) is typically lower. In the past, these observations led to suggestions that valley networks formed by groundwater sapping [Laity and Malin, 1985; Malin and Carr, 1999], subice flows [Clow, 1987], or hydrothermal seepage [Dohm and Tanaka, 1999]. Late Hesperian and Amazonian times conversely are assumed to have been dry and cold on the basis of the paucity of valley networks on the landforms of these ages. However, Mangold et al. [2004] have noted the occurrence of dense drainage networks within Valles Marineris, dated as Late Hesperian. The attributes of these networks are also consistent with warm and wet atmospheric conditions. Mangold et al. [2004] cited two primary locations: Echus plateau, around Valles Marineris and Melas Chasma within Valles Marineris. In this paper, we describe the valley networks of Melas Chasma and the nature of the substratum. We then provide evidence for the development of a body of standing water that is connected to the valley networks. We also determine the ages of the different surfaces using crater counting techniques. All these observations are crosscorrelated so that an origin and timing of the valley networks and the putative paleolake can be proposed. The possibility 

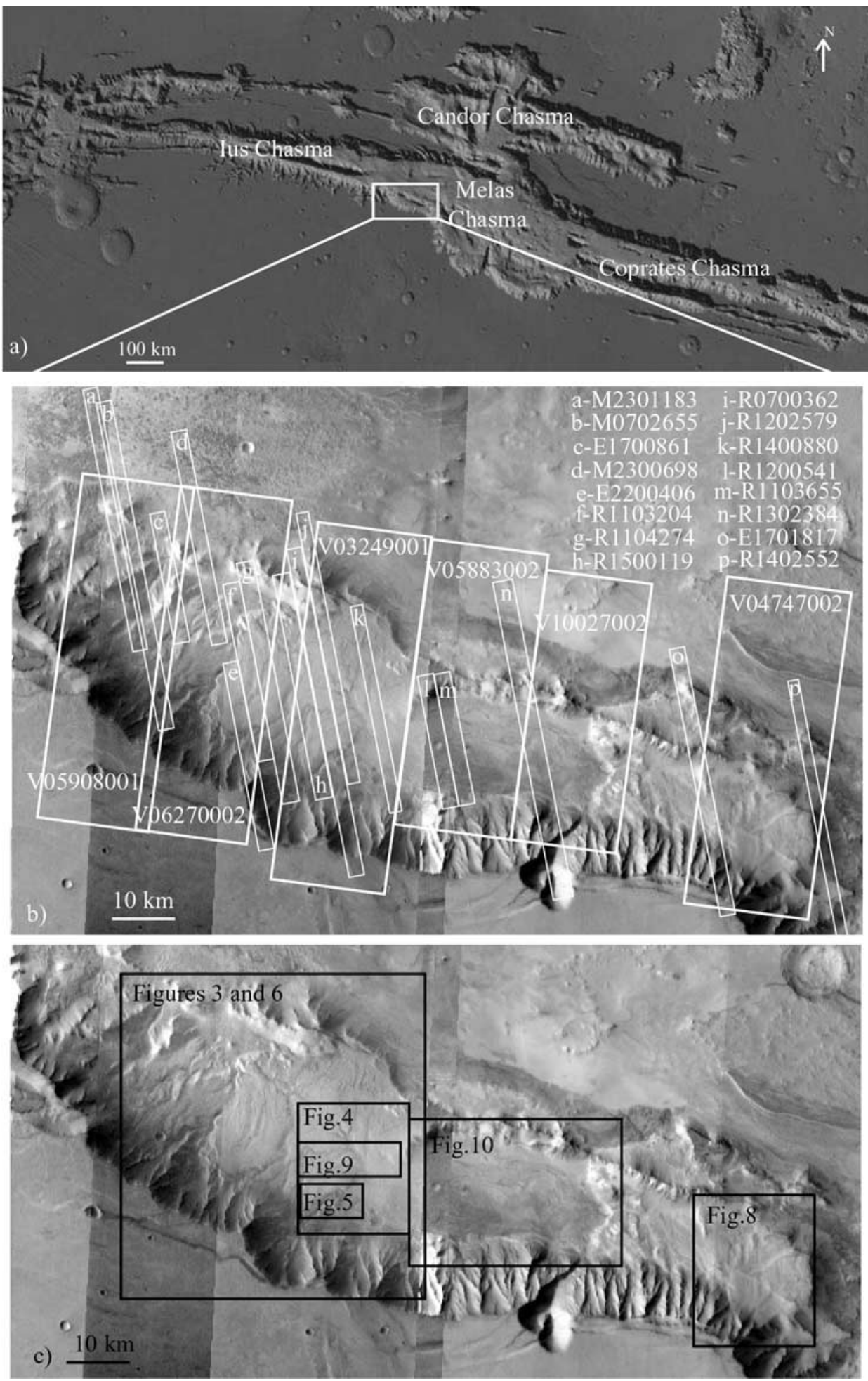

Figure 1. The study area: (a) the location within Valles Marineris, (b) the location of MOC and THEMIS visible images used in this study, and (c) the location of figures presented in this paper.

that warm and wet climatic conditions occurred during the formation of Valles Marineris history is discussed.

\section{Geological Setting}

[4] The area of study is located in Western Melas Chasma, at the eastern end of Ius Chasma (Figure 1). Melas
Chasma, the central part of Valles Marineris displays layered deposits and provides valuable information about the geological history of the canyon system. Because of geology of this area, it was considered as a high-priority landing site for MER rovers [Weitz et al., 2003]. The geology of western Melas Chasma was studied from Mars Global Surveyor mission (MGS) remote sensing data 

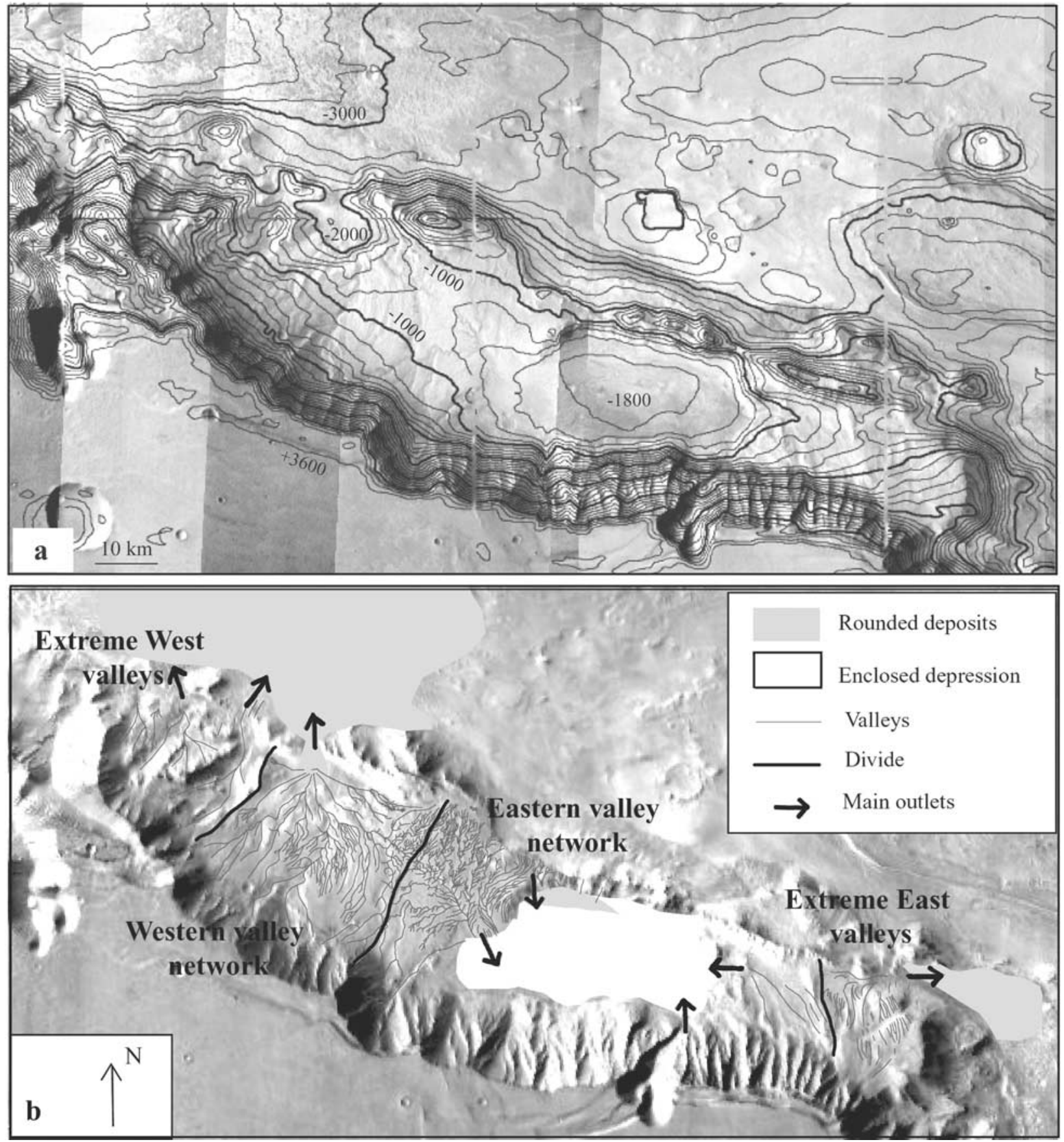

Figure 2. (a) Topographic context: contour lines from MOLA data superposed on mosaic of daytime THEMIS images. The interval of the contour lines is $200 \mathrm{~m}$ and the lines are in bold every $1000 \mathrm{~m}$. (b) Simplified geological map: distribution of the valleys and the main deposits.

[Pelkey and Jakosky, 2002], and the surficial properties were analyzed from Mars Odyssey THermal EMission Imaging System (THEMIS) data [Pelkey et al., 2003]. Both studies concluded that the Chasma has had a complex history mainly dominated primarily by eolian processes in the recent period of time.

[5] The area studied in this paper corresponds to an inner plateau of Melas Chasma perched at around $2 \mathrm{~km}$ above the central canyon floor (Figure 2). The area is a hanging depression about $30 \mathrm{~km}$ wide and $120 \mathrm{~km}$ long, isolated from the canyon by mound at maximum elevation of +
$400 \mathrm{~m}$. The area is open to the canyon in Northwest (isoelevation of $-2000 \mathrm{~m}$, Figure 2) whereas to the east, there is no outlet to the canyon floor of Melas; instead, a completely enclosed depression occurs at an elevation of $-1800 \mathrm{~m}$ (Figure 2).

\section{Data Processing}

[6] Our work incorporates multiple remote sensing data from both MGS and Mars Odyssey missions. These data were incorporated into a Geographic Information System 

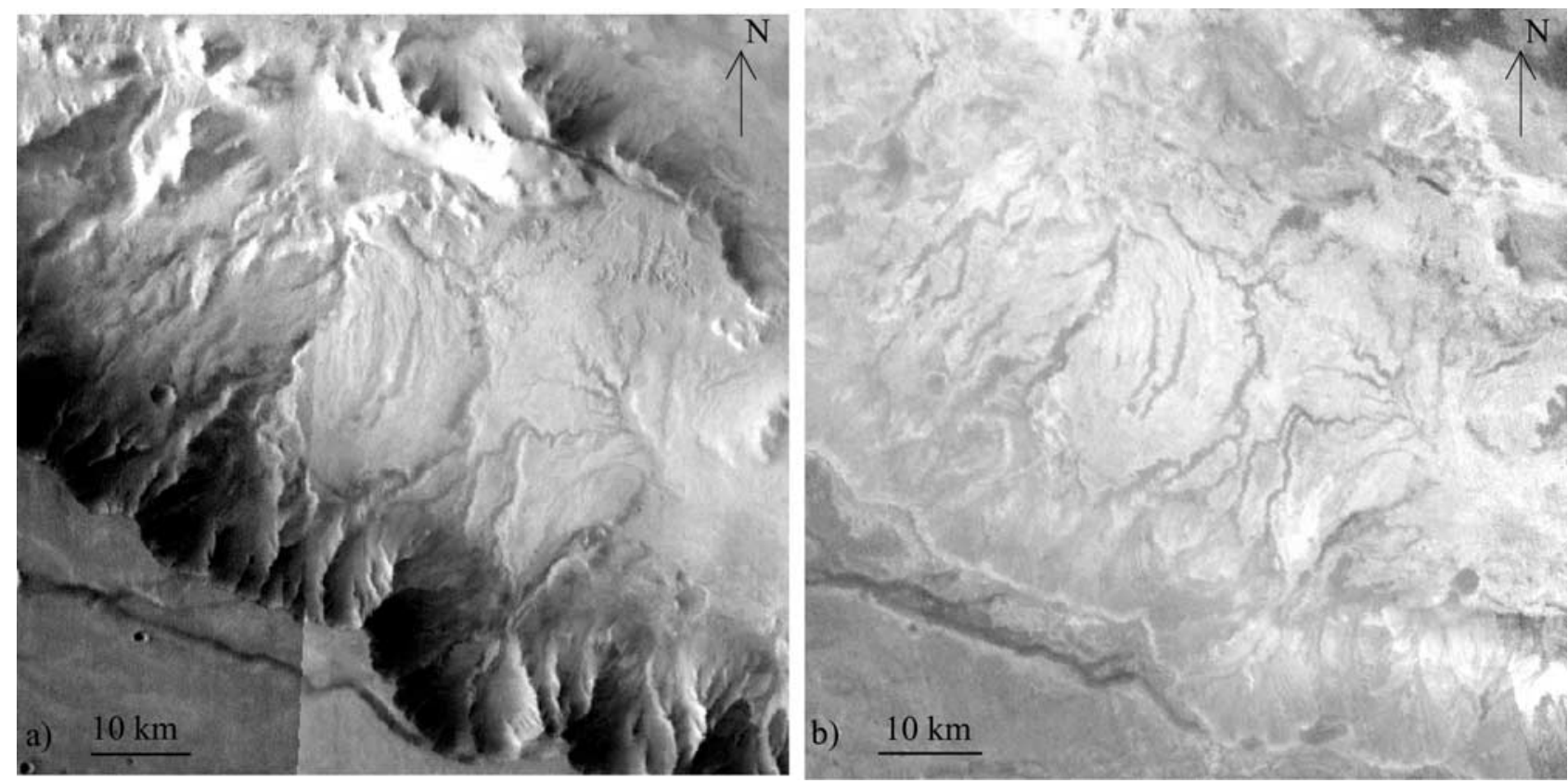

Figure 3. Infrared THEMIS images displaying the valley networks of Melas Chasma: (a) daytime and (b) nighttime.

(GIS) which superimposes a Digital Elevation Model (DEM, spatial resolution of $300 \mathrm{~m}$ ) from Mars Orbiter Laser Altimeter data, a mosaic of nighttime THEMIS infrared images (spatial resolution of $100 \mathrm{~m}$ ), a mosaic of daytime THEMIS infrared images (spatial resolution of $100 \mathrm{~m}$ ), available THEMIS visible images (spatial resolution of $18 \mathrm{~m}$ ) and available Mars Orbiter Camera (MOC) images (spatial resolution from 1.4 to $15 \mathrm{~m}$ ).

[7] Both the MOLA DEM and the daytime THEMIS IR mosaic provide the broad geological context. The nighttime THEMIS mosaic provides information about the thermal properties of the surface. For instance, the parts covered by dust mantle are identified because of their low thermal inertia (related to rock properties) and their low temperature during the night [Christensen et al., 2003]. The Visible THEMIS images which cover almost the entire studied area (Figure 1b) are at an optimal resolution to study the details of the surface of Mars. Due to their high resolution, the MOC images display small details of the surface, but cover a limited area. The placement of these images in a THEMIS context allows us to unambiguously identify small scale surface features.

\section{Valleys of Melas Chasma}

\subsection{Characteristics of Melas Chasma Valleys}

[8] Nighttime infrared THEMIS images reveal a dense system of valley networks, which are not readily apparent in visible wavelengths (Figure 3 ).

[9] Widths of valley network segments range from $50 \mathrm{~m}$ to $2 \mathrm{~km}$, and depths are estimated from several meters to $150 \mathrm{~m}$ (Figure 4). Sides of valleys are not rectilinear, and show many small incised tributary valleys (Figure 4d). Upstream cross profiles of valleys are very acute (Figure 4a). Downstream profiles are altered, i.e., the valleys are floored by alluvial deposits (Figure 4b). Some of the valleys consist of incised meanders (Figure 4a). Meander belt widths range from 500 to $1,600 \mathrm{~m}$, and wavelengths from 800 to $2,000 \mathrm{~m}$.

[10] At the scale of THEMIS visible images, inner channels have been observed on the floor of one of the valleys (Figure 4b). MOC Images also reveal that the valleys contain small channels within them (Figure 4d). These channels are in the order of ten meters wide. The valley floors are veneered by large scale, transverse and gently sinuous dunes. The inner channels are filled by smaller dunes (Figure 4d).

[11] The topography of the outlet of the valleys is convex downslope, indicative of a depositional fan. The MOC imagery reveals a distributary system of channels at the fan surface (Figure 4c). Both sides of the fan are partly eroded (Figure 4a).

[12] A distinct valley crosscuts the valley network described above (Figure 4a and Figure 5). This valley begins at the base of the Melas Chasma wallslopes and has no connection to any other valley: neither affluent or confluent. The valley width is $1.5 \mathrm{~km}$, for a depth of $40 \mathrm{~m}$. The floor of this valley displays an incised bench (Figure 5).

\subsection{Interpretation}

[13] On Earth, incised fluvial valleys have a typical narrow and acute transverse profile whereas glacial valleys are U-shaped due to erosion by ice. Morphologies of Melas valleys are consistent with fluvial erosion. The number of tributaries on the sides of the valleys suggest formation by surface runoff as opposed to sapping processes. Sapping processes would have left undissected sections and large valleys without tributaries. Conversely, the valley coming from the toe of the wallslopes, and crosscutting the others, does not show any tributary and therefore could be related to sapping. The observation of inner channels suggests that running water flowed within these valleys. These channels 

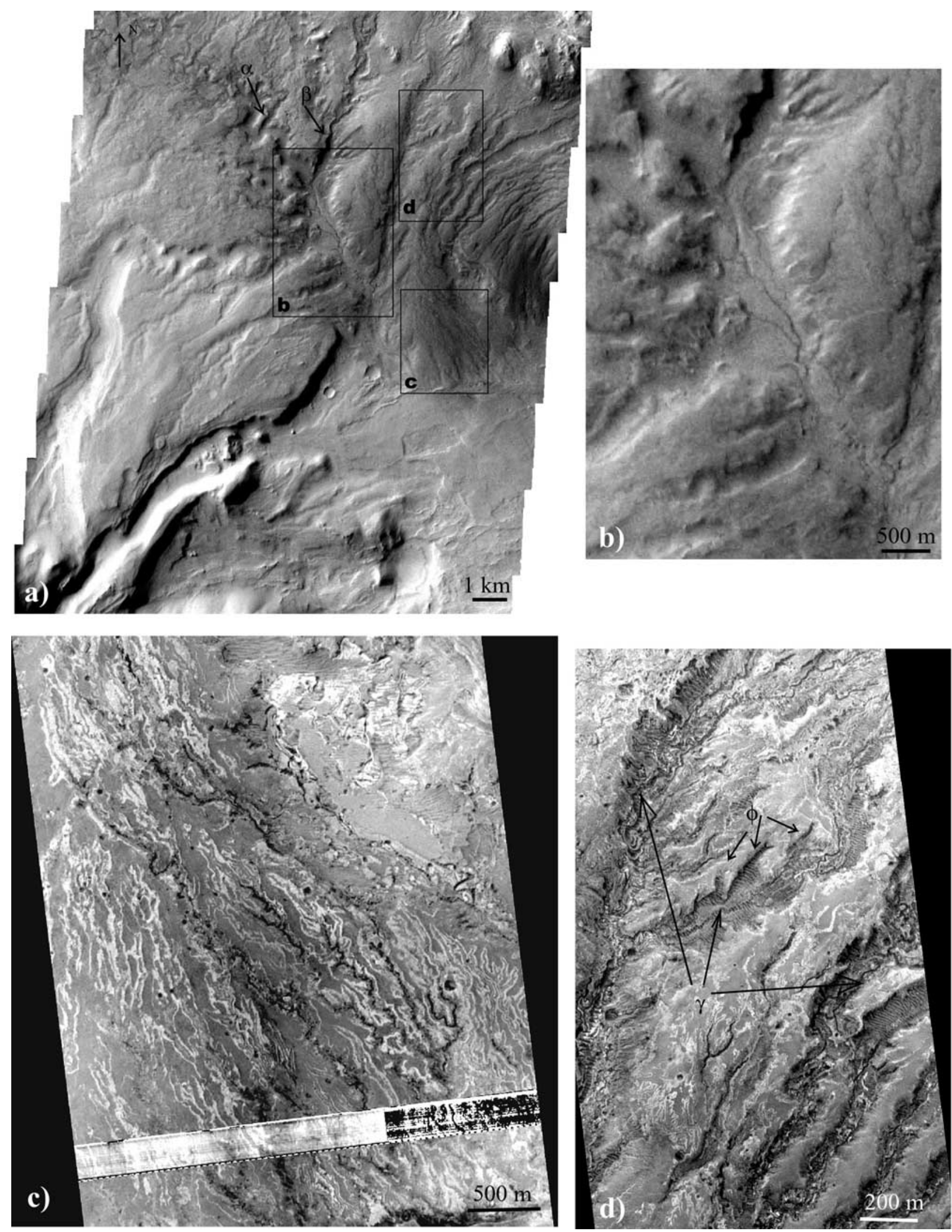

Figure 4 

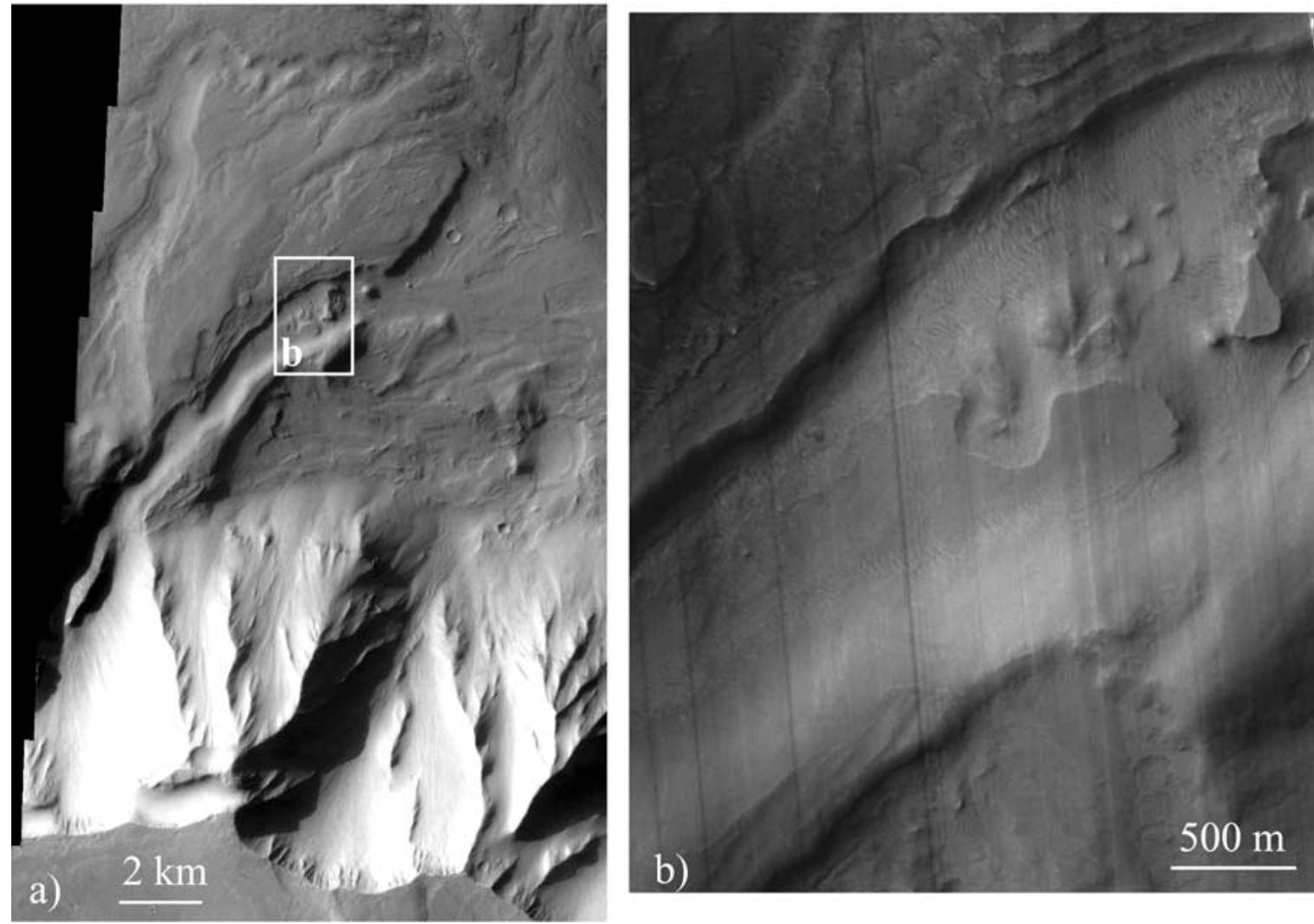

Figure 5. The late valley. (a) Part of the THEMIS image V03249001 showing the crosscutting relation between the main valley network and the late valley. (b) Part of MOC image e1701817: enlargement on the floor of the late valley.

obviously are underfit, so that smaller channels occupy the once-larger channels in an underfit relationship. Viking and initial analyses of MOC data suggest that there were no channels within Martian valley networks, which sheds doubt on their erosion by precipitation and surface runoff [Carr and Malin, 2000]. Much higher resolved images in Melas Chasma reveal the occurrence of inner channels, the least equivocal diagnostic attribute for past running water at the surface of Mars.

[14] The dimensions of the valleys are similar to terrestrial ones in terms of length, width and depth and also in term of characteristics of the meanders such as wavelength and spacing. Meanders form as banks are eroded, and adjacent banks are aggraded, which takes lot of time. Meanders are indicative of prolonged surface flow.

[15] The fan lying at the outlet of the valleys is interpreted as an alluvial fan, which is defined as a fan-shaped accumulation of sediments traversed by stream flows [Leeder, 1999]. Specifically, the general pattern drawn by the channels at the surface of the fan suggests a braided fluvial-type fan [Stanistreet and McCarthy, 1993]. The flanks of the alluvial fan are truncated by adjacent valleys, implying that the valleys postdate the formation of the alluvial fan. These observations suggest that the area could have undergone several wet phases.

[16] The single valley crosscutting all the others attests to an ultimate fluvial episode over the area of study, after the main one shaped the main valley networks. This attests to the poly-phased fluvial history of the area.

[17] Most of the valleys are filled with transverse sand dunes. The topography of the valley networks could generate katabatic winds that cause loose material within the valley to be blown into dunes. In current desertic areas of Earth, e.g., Sahara, the filling with sand of valley networks by recent eolian material is a very common feature. The Sahara valley networks formed under wet climatic conditions and are currently buried by sand under dry conditions [McCauley et al., 1982].

\section{Valley Network Organizations}

5.1. Identification of Valley Networks and Watersheds

[18] Available THEMIS and MOC images were used to map the valleys in the study area. A comprehensive map of

Figure 4. Morphological details of the eastern valley network. (a) Part of THEMIS Visible image V03249001 showing the valleys of the eastern Network. Some of the valleys have meanders $(\alpha)$, and some valleys are very narrow $(\beta)$. (b) Enlargement on the central valley showing well-preserved inner channels. (c) Part of MOC image R1400880 showing on the fan at the outlet of the valleys. (d) Part of MOC image R1400880 showing on the valleys; $\gamma$ indicates small inner channels, and $\Phi$ indicates the tributaries of the valleys. 

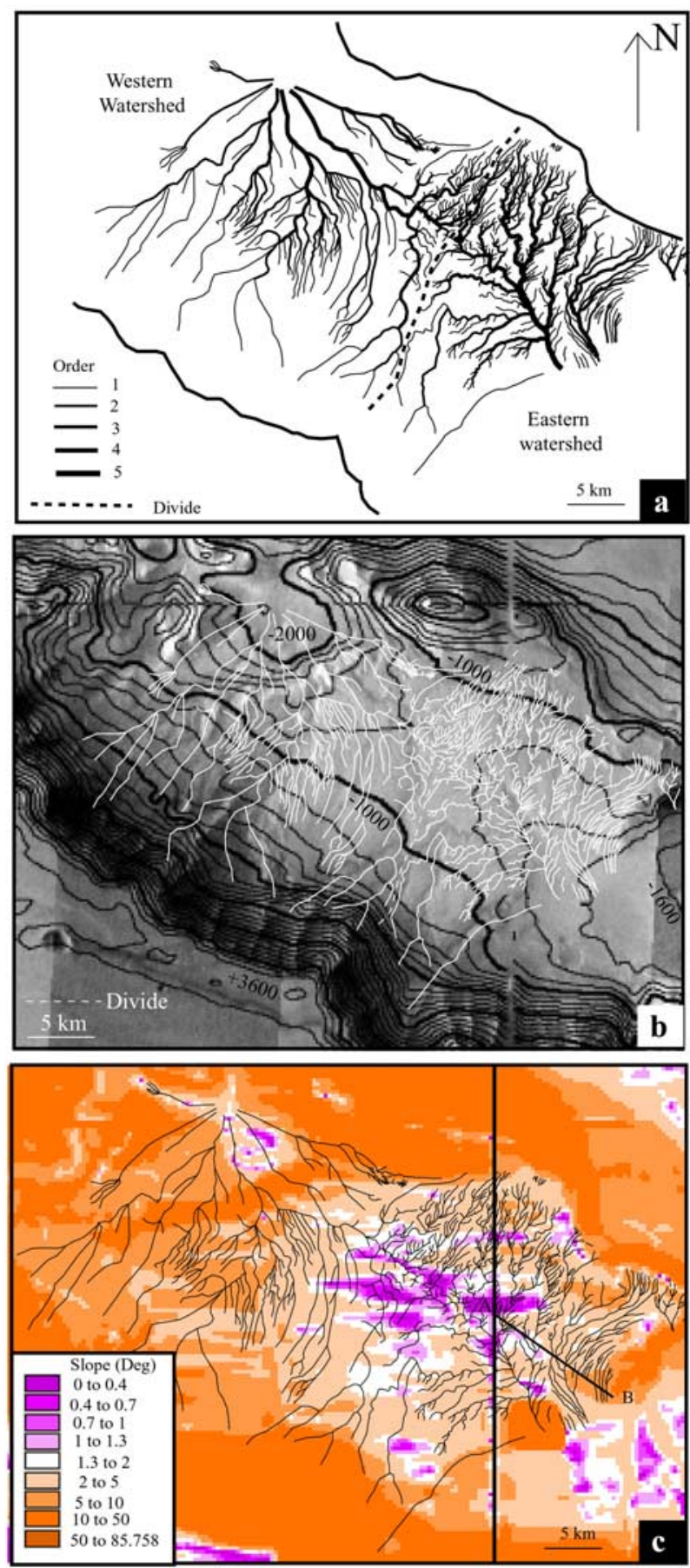

Figure 6. (a) The valley networks in Melas Chasma: The thickness of the valleys relates to their hierarchical order. The dashed line represents the natural divide separating both valley networks. (b) The valley networks placed into the topographic context. The headwater areas are scattered at different elevation. (c) A map of slope and the valley networks. The slope map is derived from altimetric MOLA data. The color graduation highlights the threshold value of $1.3^{\circ}$ of slope below which (in pink colors) the runoff pattern is dendritic and above which (in amber colors) it is parallel. these valley networks is provided in Figure 2b. Valleys are observed on the whole studied area from extreme west to the extreme east corresponding with at least 4 different drainage basins. The valleys flow into Melas Chasma for the western and the extreme eastern valley networks. A part of the extreme eastern valley network and the eastern valley network flow into the enclosed depression at the center of the study area. To study the characteristics of the valley networks, we focused detailed analyses on the western and the eastern systems which are separated by a common drainage divide (Figure $2 \mathrm{~b}$ and Figure $6 \mathrm{a}$ ).

\subsection{Characteristics of Valley Networks}

[19] Drainage densities, or the ratio between the cumulative length of the valleys and the total drainage area, were computed through the GIS. We found drainage densities at 1.1 and $1.5 \mathrm{~km}^{-1}$ for the western and eastern systems, respectively. In order to study the growth of the drainage networks, the valleys were classified by taking the shortest tributary as a first order stream $(n=1)$, and successive $n+$ 1 order being generated at each junction of two $n$ order streams [Horton, 1945]. The western and eastern networks are fourth- and fifth-order drainage systems, respectively, both corresponding to high degrees of branching (Figure 6a).

[20] The combination of the MOLA DEM and digital maps of the drainage networks reveals that valley heads are located over a wide range of elevations (Figure 6b): (1) about $-1,000 \mathrm{~m}$ on both sides of the transverse drainage divide, (2) $0 \mathrm{~m}$ for the valleys starting at the toe of the southern wallslope of Melas Chasma, and (3) $-800 \mathrm{~m}$ for the valleys on the opposite perched interior plateau.

[21] A map of local slopes was derived from the MOLA DEM, and combined with a digital map of the drainage networks (Figure 6c). We found a relationship between slope and the pattern of the valley networks. Across the $\mathrm{AB}$ profile (Figure $6 \mathrm{c}$ ), the correlation points to a threshold value for the slope of $1.3^{\circ}$ below which the pattern is dentritic, and above which the pattern becomes subparallel [Schumm, 1977; Phillips and Schumm, 1987; Mangold et al., 2004].

\subsection{Interpretation}

[22] The Martian valley networks studied here display an earth-like drainage density, i.e., higher than $1 \mathrm{~km}^{-1}$ for networks mapped at THEMIS visible image resolution (spatial resolution of $18 \mathrm{~m}$ ). Terrestrial drainage densities range from 2 to $30 \mathrm{~km}^{-1}$ [Carr and Chuang, 1997]. For comparison, the valley networks of the Noachian highlands mapped with Viking images (spatial resolution of around $200 \mathrm{~m}$ ) have a density of $0.01 \mathrm{~km}^{-1}$ [Carr and Chuang, 1997]. Conclusively, it can be stated that terrestrial and Melas Chasma valley networks share comparable features. The high degree of branching observed here attests to the maturity of the networks; those maturity are reached in several thousand years on Earth [Leopold et al., 1995].

[23] The origin of the Melas valley networks can be discussed from the distribution of the heads of the valley. The heads of the valley are located at various elevations. This distribution is indicative of atmospheric precipitation. The dendritic nature of the drainage pattern is also typical of precipitation and surface runoff. Indeed, on Earth, 


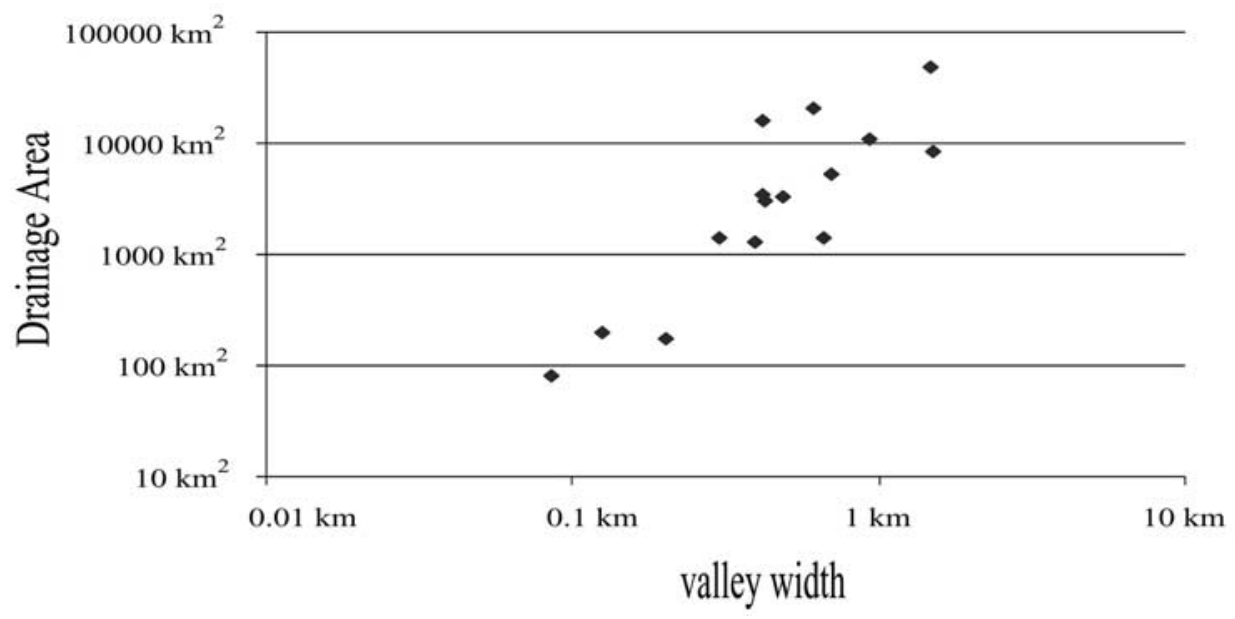

Figure 7. Graph showing the width of the valley networks and the upstream drainage area.

in case of runoff, there is a threshold value of the local slope for the geometry of the runoff. Under $1.3^{\circ}$ of slope, the networks have a dendritic pattern with orthogonal junctions whereas above this slope, the valleys are subparallel with low angle junctions [Schumm, 1977; Phillips and Schumm, 1987; Mangold et al., 2004]. This is the correlation observed for Melas Chasma valley networks.

[24] A relation between the drainage area and the discharge is expected for networks generated by precipitation. We have assumed that the current width of a valley correlates with the width of the inner channels having shaped the valley, so could be representative of the paleodischarge. We measured the width of the valley and the corresponding upstream drainage area at different points of the networks. As shown in Figure 7, we observe a relationship between the width of the valleys of Melas Chasma and the upstream drainage area. This provides an additional argument supporting formation by precipitation in the form of rainfall or snow leading to snowmelt.

[25] In summary, Melas Chasma valley networks are dense, hierarchized, mature networks similar to terrestrial stream systems, thus providing supporting evidence for past atmospheric precipitation.

\section{Layered Substratum Eroded by the Valleys 6.1. Observations}

[26] The wallslopes of the perched depression show typical spurs and gullies, as elsewhere in Valles Marineris. Inside the depression, the bedrock of the valleys is apparently composed of a very distinct lithology (Figure 8). The geological formation is layered (Figure 8b), $2 \mathrm{~km}$ thick at least, and clearly overlaps the wallslopes of Valles Marineris in the far eastern part of the studied area. The formation, including valley networks, is crosscut by straight and narrow grabens several meters deep (Figures 8a and 8c).

[27] The nature of the substratum of the valleys can be observed in other locations. Figure 9 shows two additional enlargements from MOC images attesting that the valleys are incised into a layered substratum. Other MOC images (for instance M0702655) reveal that the bedrock of the valleys is formed by light-toned deposits, like those discovered by MGS missions elsewhere [Malin and Edgett, 2000].

\subsection{Interpretations}

[28] The southern closure of the perched depression is formed by Valles Marineris wallslopes, several kilometers high, stratified by the stacking of lava flows [Peulvast et al., 2001; McEwen et al., 1999; Scott and Tanaka, 1986], and eroded into spurs and gullies. The geological formation incised by the valley networks postdates the southern wallslopes. This formation is layered over thicknesses of several kilometers, and shows light-toned deposits locally. Some canyons of Valles Marineris, as Melas Chasma, show interior layered deposits (ILD). These deposits, located in the central part of canyons, are stacked in sequences as thick as $5 \mathrm{~km}$ in some locations [McCauley et al., 1978; Nedell et al., 1987; Lucchitta et al., 1992, 1994]. The fine stratigraphy of these deposits [Malin and Edgett, 2000; Komatsu et al., 2004] includes layers of light-toned material. Considering the morphological and stratigraphical characteristics of Valles Marineris ILD, the observations of this study suggest that the valleys of Melas Chasma are emplaced on remnant layered deposits. OMEGA, the spectrometer onboard Mars Express, has revealed sulfates associated with layered deposits in Valles Marineris [Gendrin et al., 2005]. In the vicinity of the valley networks, OMEGA also reveals sulfates [Gendrin et al., 2005]. This suggests that the valleys have eroded a layered substratum possibly containing some sulfate deposits.

\section{Enclosed Depression}

\subsection{Sedimentary Figures of the Enclosed Depression}

[29] The eastern valleys networks converge to a subcircular, perched depression, the bottom of which is approximately $-1800 \mathrm{~m}$ (Figure 2). The outline of this depression can easily be mapped with THEMIS Visible image (Figure 10a). The study of the DEM in combination with these observations reveals that this outline fits with a single elevation contour (Figure 11).

[30] We have observed fan deposits at two opposite sides of this depression (Figure 10 and 11). Both fans (Fan 1 and Fan 2 in Figure 11) are localized at the outlet of valley 

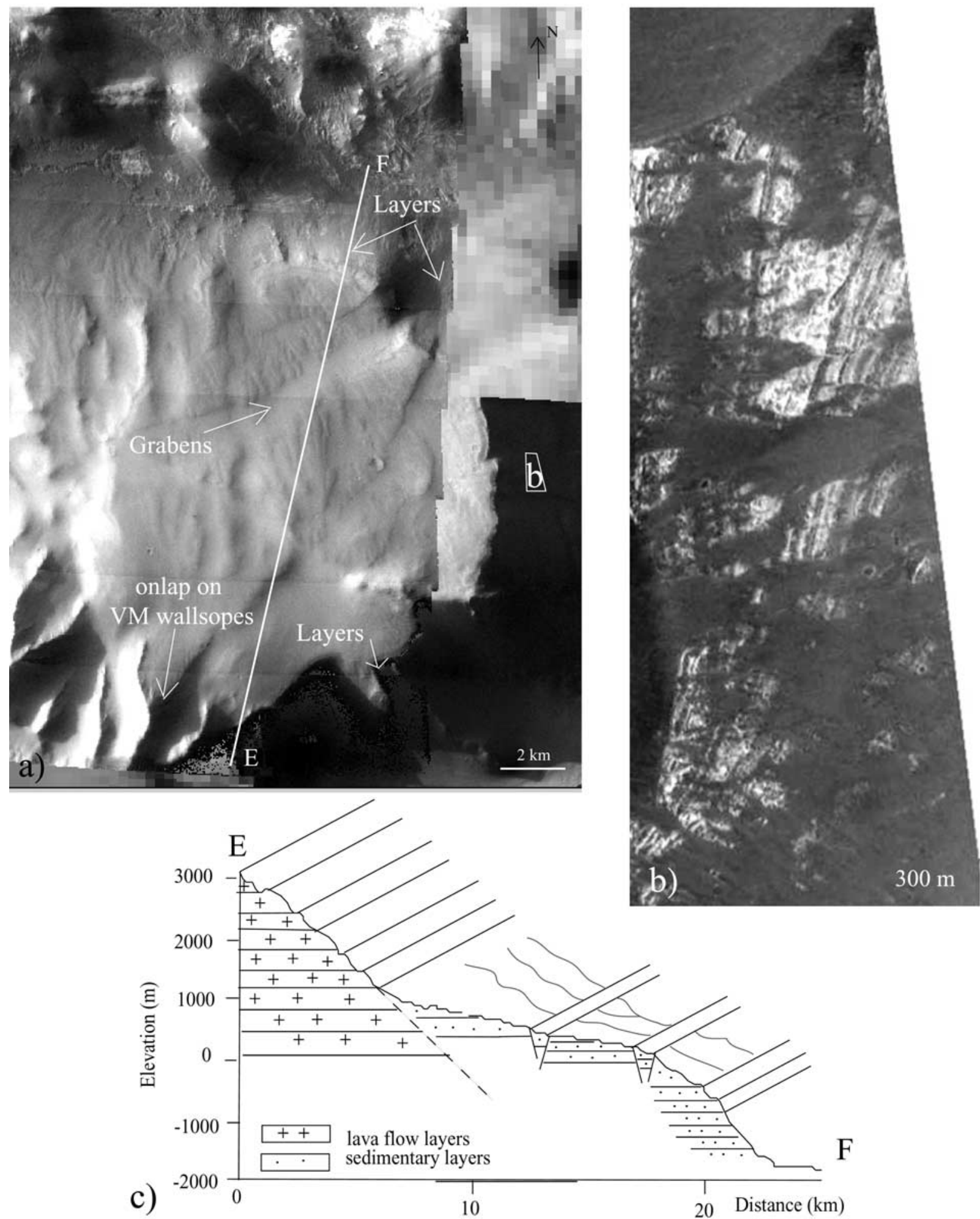

Figure 8. Substratum on which valley networks are emplaced. (a) Part of THEMIS image V04747002. (b) Enlargement of MOC image R1402552 showing the flank of the geological formation where the valleys incised. (c) Interpretative 3-D diagram of THEMIS image V04747002 across profile EF (Figure 10a). The substratum on which the valley networks are observed overlaps the Valles Marineris wallslopes. The layered substratum and the valley networks cut the grabens. 

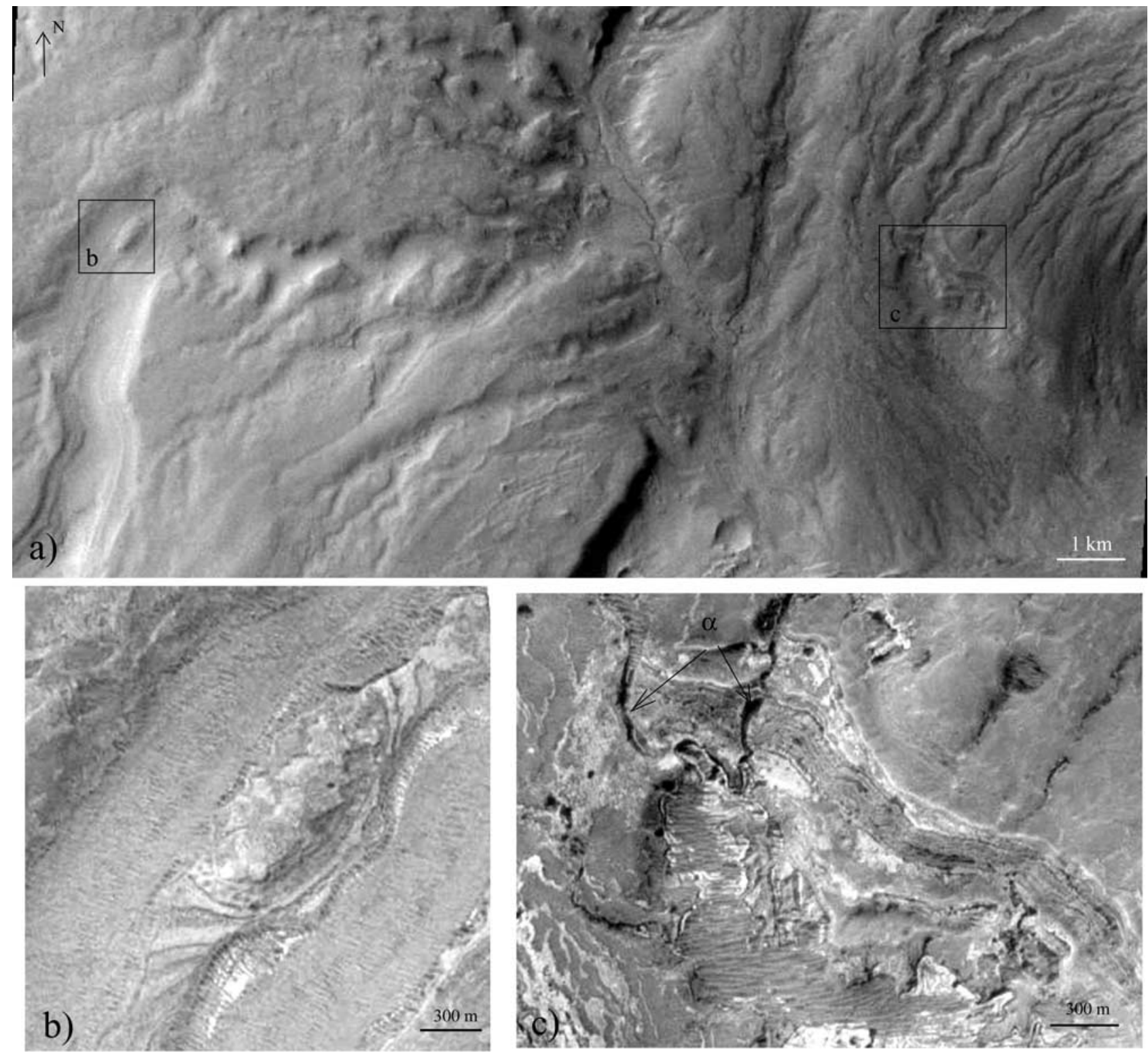

Figure 9. Evidence of layered substratum. (a) Context of THEMIS images shown in Figures 9b and 9c. (b) View of a layered interfluve between two main valleys. (c) Small scarp showing the outcropping of the layered substratum. Valleys incised into layers $(\alpha)$.

networks. Fan 1 is made up of material with divergent finger-like terminations emphasized by alternations of fine layers of dark and light-toned material (Figure 10b). The surface of Fan 1 is rough and complex (Figure 10b).

[31] Both fans overlap the layers exposed throughout the depression (Figure 10). In detail, the layers, a few meters thick, are made up of interbedded material with different tone and texture (Figure 10d). North of the depression, there are complex features, referred to as rounded deposits (Figure 10d), at the top of the layered unit. The rounded deposits are locally covered by dark sand dunes, similar to the eolian dunes encountered within the valley networks. Both rounded deposits and sand dunes are bounded at the south by a straight border (Figure 10d). Similar rounded deposits have already been described on the floor of Melas Chasma, and interpreted as block deposits derived from the erosion of the ILD [Weitz et al., 2003]. Our study reveals that the rounded deposits described by Weitz et al. [2003] on the floor of Melas Chasma and the rounded deposits observed in the enclosed depression are situated at the outlet of valley networks (Figure 2b). These deposits may be related to the fluvial activity.

[32] The layers at the base of the rounded deposits revealed by MOC images can be drawn all around the depression (Figure 10a). We have mapped these layers using THEMIS visible images and MOLA data and found that the layers dip toward the center of the depression (Figures $11 \mathrm{~b}$ and $11 \mathrm{c}$ ). The layers seen on the side of the depression have dips close to $3^{\circ}$.

[33] The exposed rocks in a deep depression of Melas Chasma, which are interpreted to be an erosional window, show encased channels organized in a typical dendritic 

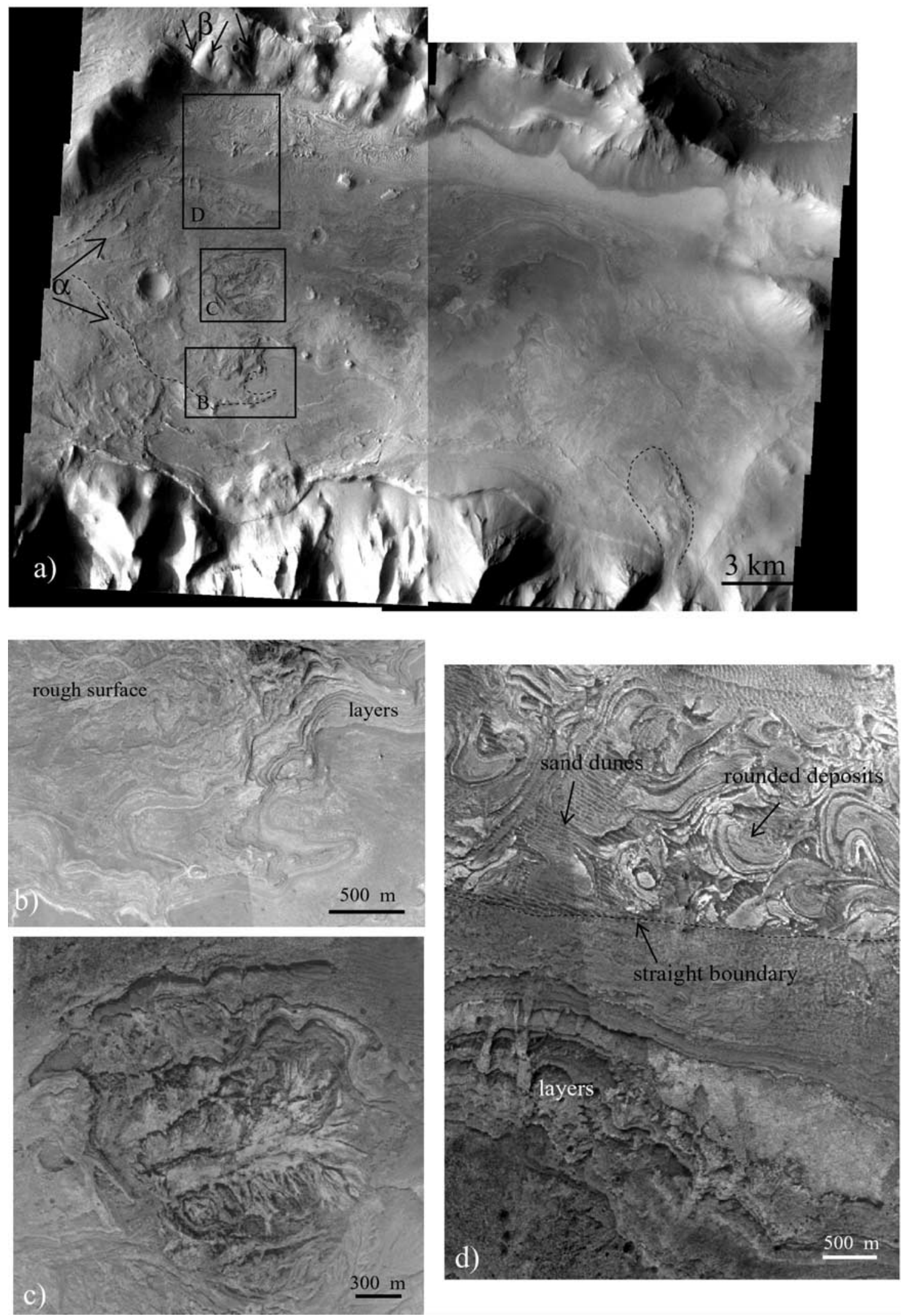

Figure 10 

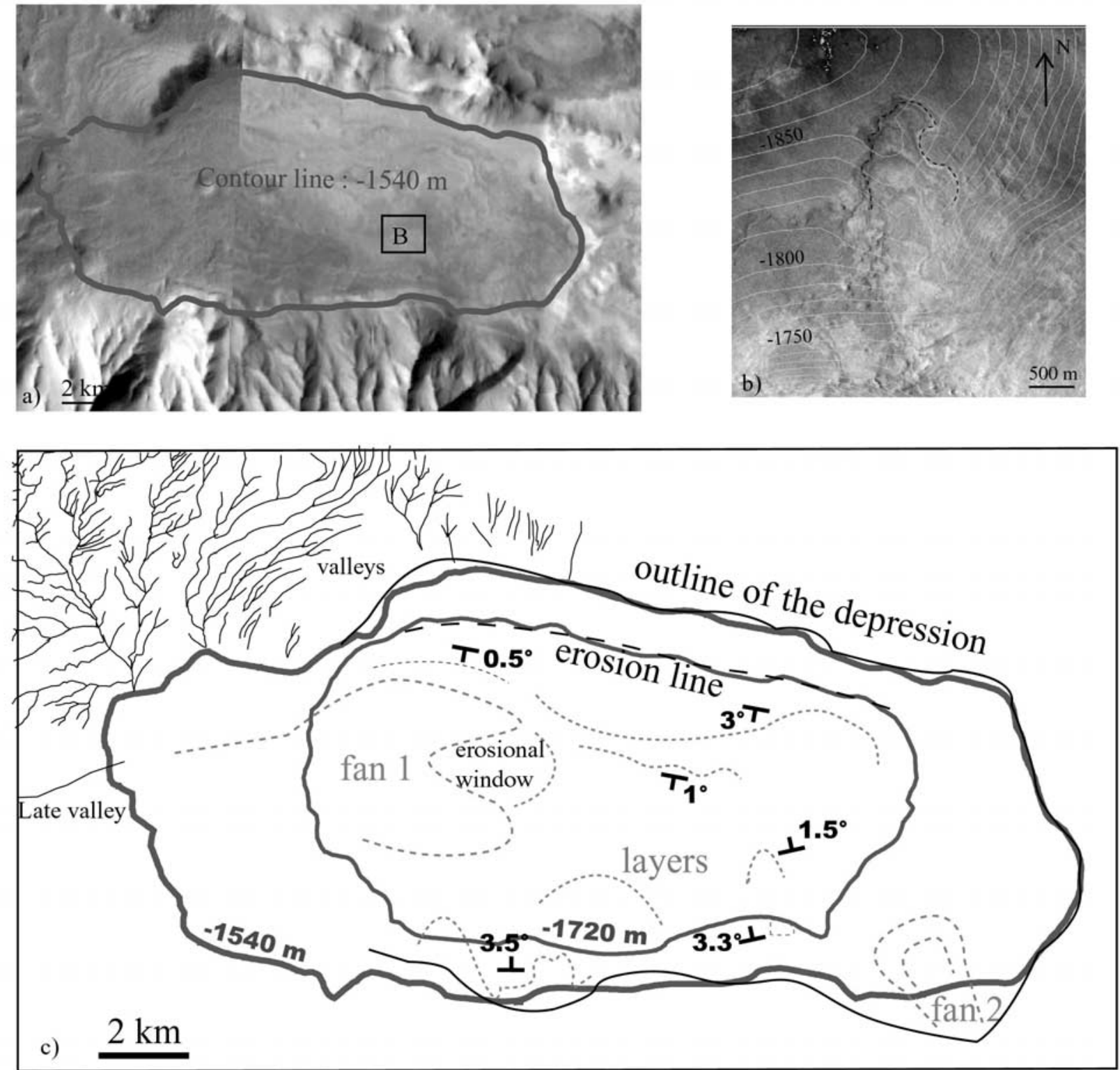

Figure 11. (a) Comparison between the contour line $-1540 \mathrm{~m}$ and the enclosed depression. (b) Example showing the crossing between a layer outline and the contour lines in the small depression. This example gives an approximate dip of $1.5^{\circ}$ northward for the dotted underlying layer. (c) Sketch of the main features and morphologies of the enclosed depression.

pattern converging toward the center of the depression (Figure 10c).

\subsection{Evidence for a Paleolake}

[34] The observation that the outline of the depression follows a contour line suggests that it may correspond to a shoreline (Figure 11c), and that it may have once contained a standing body of water. This interpretation is also in agreement with the evidence for fluvial activity upstream of the depression. Using MOLA topographic data, the corresponding water volume has been estimated to be $157 \mathrm{~km}^{3}$. The estimated drainage area of putative Melas

Figure 10. Morphology of the enclosed depression. (a) Mosaic of THEMIS images V05883002 and V10027002 and locations of Figures 10b, 10c, and 10d. A fan is revealed by a characteristic diverging material deposit $(\alpha)$ located at the outlet of the eastern valley network. Valleys $(\beta)$ on the north rim of the depression flow into the enclosed depression. A second fan is observed to the east. Both fans are outlined with dotted lines. (b) Enlargement on the distal part of the fan. The surface of the fan is rough, and the end of the fan reveals fine layers. (c) Enlargement on an erosional window showing a dentritic pattern. (d) Enlargement on the north periphery of the depression showing rounded deposits and layered deposits. 
Table 1. Estimate of the Eroded and Settled Volume of the Processes Studied Here ${ }^{\mathrm{a}}$

\begin{tabular}{lcc}
\hline & & Volume, $\mathrm{km}^{3}$ \\
\hline & Valley Networks & 14 \\
Eastern valley network & & 0.5 \\
Late valley & & \\
& Enclosed Depression & 78 \\
Layers & & 0.1 \\
Delta fan &
\end{tabular}

${ }^{a}$ The volume eroded by the valley network was estimated using the measured length of all the valleys and their width. The depth of the valley has been estimated with a scale relationship between the width and the depth (Depth $=0.16^{*}$ Width $^{\wedge}{ }^{0.72}$ ). The apparent volume eroded by the late valley was estimated as the void volume between the current edges of the valley computed from MOLA data. The deposited volume of the delta fan was estimated by computing the area of the deposit and the mean thickness estimated on images. The volume of the layers has been estimated by subtracting the current topography to the elevation of $-1920 \mathrm{~m}$, the lowest elevation of the enclosed depression.

lake is $395 \mathrm{~km}^{2}$. This last value is a minimum estimate because our calculation assumes that the southern Valles Marineris wallslopes are the boundaries of the drainage area.

[35] The fans (Fans 1 and 2 in Figure 11) do not display any channel on their surface, suggesting they may be delta fans (i.e., subaequeous alluvial fans [Leeder, 1999]). In addition, the apex of Fan 1 (Figure 11c) corresponds to the elevation of the border line of the entire depression. On the other hand, the apex of Fan 2 does not, but it does at the same elevation as the southern straight boundary of the rounded deposits (Figure 11c). That suggests that the two fans have formed during two distinct water levels.

[36] It is of interest to note that the southern straight boundary of the rounded deposits also crosscuts the sand dunes lying above. This truncation of both rounded deposit and eolian dunes suggests an erosional episode posterior to the formation of the rounded deposits and sand dunes.

[37] The origin of the layers in the depression is difficult to explain. Indeed, there is evidence suggesting that the valleys eroded into remnant layered deposits. A plausible interpretation is that the layers are bedrock at the bottom of the depression. The alternative hypothesis is that the layers within the depression originated by lacustrine sedimentation within the depression, and therefore reflect recycled ILD material. The general synform structure of these layers could reflect typical lacustrine sedimentation, with deposits onlapping a former depression and downlapping toward the center. For instance, the dip of the lacustrine sediments in the flanks of Leman lake (Switzerland) is close to $3^{\circ}$, like in Melas putative paleolake [Girardclos, 2001].

[38] The layers exposed in the depression have been deeply eroded. The origin of this erosion remains uncertain, and could be related to eolian activity. The dentritic pattern exposed in the erosional window corresponds to the base of the stratigraphic pile. This pattern may be exhumed runoff channels or a delta, which would attest to the complex history of the layers. Alternatively, the dendritic pattern could be much younger and is superposed on these layers which would agree with the hypothesis that surface runoff occurred much later in the area. The dentritic pattern converges toward the center of the erosional window but the exact relationship between this pattern and the local slope is beyond the resolution of MOLA data, so the relative timing is difficult to assess.

\subsection{Sedimentary Balances}

[39] To determine the genetic relationship between the valleys, fans and layers located in the depression, we have tentatively estimated eroded and settled volumes. We used MOLA gridded data and MOC and THEMIS images when the structures were beyond the resolution of MOLA data. These estimates bear large uncertainties. First, some depths or thicknesses have been estimated from images, which is a source of error. Second, the estimates are minimum as well as maximum. The aim of these estimates is just to assess the order of magnitude of the flux of the sedimentary material.

[40] The estimated volume eroded by the eastern valley network that converges toward the enclosed depression is $\sim 14 \mathrm{~km}^{3}$, and the volume removed by the late valley is $\sim 0.5 \mathrm{~km}^{3}$ (Table 1). These values are minimum estimations because the valleys could have been eroded and filled by eolian processes. The volume of Fan 1 at the outlet of these erosional areas is $\sim 0.1 \mathrm{~km}^{3}$.

[41] These results rule out the possibility that the bulk of Fan 1 is the whole material eroded by the valley networks. Conversely, the volume deposited by the fan is on the same order as the volume eroded by the late valley, suggesting a relationship. This also implies that the valley network is older than this event. This relative chronology is supported by the morphological detail showing that the material of delta fan (i.e., Fan 1) clearly postdates the alluvial fan associated with the valley network (Figure 12).

[42] To investigate the fate of the sediments eroded by the valley networks, we tried to estimate the volume of the layers in the enclosed depression. The volume of the layers has been estimated subtracting the current topography to the elevation of $-1920 \mathrm{~m}$, the lowest elevation of the enclosed depression. Our calculation yields a volume of $78 \mathrm{~km}^{3}$ (Table 1). This value should be considered as a rough estimation because the layers have partly been removed, and because we have no idea of the unexposed geometry of these layers. The valley network with a minimum eroded volume of $14 \mathrm{~km}^{3}$ is only a part of the watershed converging toward the enclosed depression. The values of volume could thus be consistent with the hypothesis of lacustrine sedimentation supplied by the activity of the valley networks. According to this hypothesis, the layers observed in the depression would be lacustrine layers made up of reworked material from the valley network bedrock, and not the layers composing this bedrock.

\section{Ages of Valley Networks}

[43] The location of the valley networks and the paleolake within Valles Marineris gives an upper limit to the ages of the valley networks. According to Scott and Tanaka [1986], Valles Marineris formed during the Hesperian which began around 3.7 Gy to 3.3 or 2.9 Gy [Hartmann and Neukum, 2001]. So all the landforms described in this paper should be younger than $3.7 \mathrm{~Gy}$. In order to refine the age of the valleys networks and the paleolake, we have investigated the impact crater populations of the surfaces where the valleys and lake were formed. All available images were used to assess the crater populations. Using the diagram 

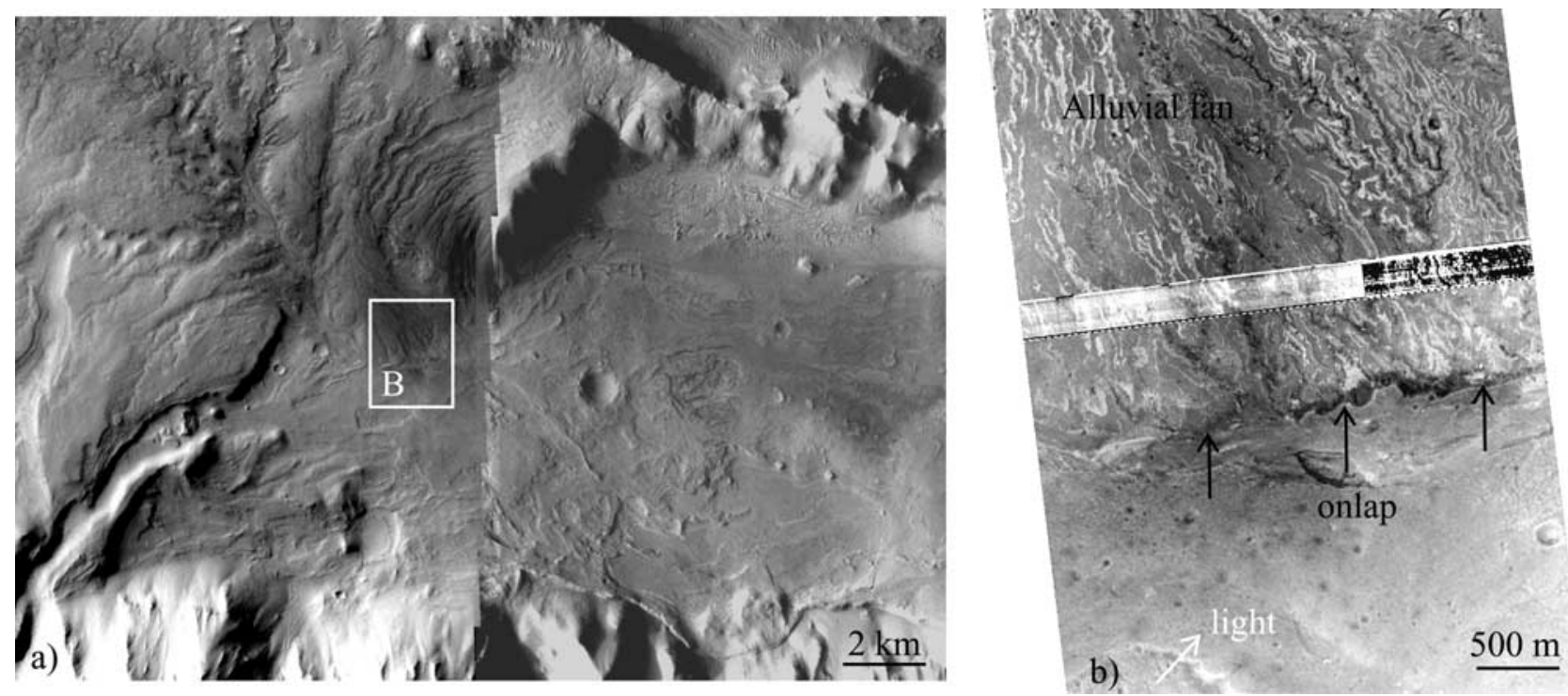

Figure 12. (a) THEMIS Visible mosaic showing the contact between valley networks and the enclosed depression. (b) Enlargement of the contact between the alluvial fan related to the valley network and the delta fan (Fan 1 in Figure 11). We observe that the material of the delta fan overlies the alluvial fan $(\alpha)$.

from Hartmann [1999] where size of craters are plotted against their density, we estimated ages of surface units [Hartmann, 1999; Hartmann and Neukum, 2001]. Generally speaking, the study area is depleted in impact craters compared to the floor of Valles Marineris which dates to the beginning of the canyon history [Quantin et al., 2004]. This observation suggests a complex history for the study area.

[44] Figure 13 shows the crater size distribution of the paleolake (Figure 13a), and the crater size distribution of the valley networks (Figure 13b). Both distributions are complex showing portions that follow the isochrones which are used to interpret ages and portions crosscutting the isochrones which may indicate resurfacing processes. The largest craters $(>500 \mathrm{~m})$ give an age around $3 \mathrm{~Gy}$, followed by a rejuvenation between 3 Gy and 200 My for craters between 250 and $350 \mathrm{~m}$. The distribution then follows the isochron of $200 \mathrm{My}$ and shows a resurfacing pattern until $10 \mathrm{My}$. These results suggest that the current topography and substratum of both the valley networks and the paleolake date from the beginning of Valles Marineris history ( $\sim 3.5$ Gy). This suggests that the erosion of the layers of the paleolake is dated back to beginning of Valles Marineris history. Next, resurfacing processes occurred erasing the record of impact craters $<500 \mathrm{~m}$ (part of the distribution between 3.5 Gy and $200 \mathrm{My}$ ). Assuming a ratio of crater depth/diameter of $1 / 5$, the craters whose depth is shallower than $70 \mathrm{~m}$ would have been erased after 3.5 Gy by these resurfacing processes. Accordingly, the valley depths which range from several meters to 150 meters should be younger than 3.5 Gy. After $200 \mathrm{My}$, the crater size distribution displays a more regular erosion pattern crossing isochron which could be attributed to a regular eolian activity.

\section{Discussion}

\subsection{Origin of Melas Chasma Valley Networks}

[45] Inner channels observed within some valley networks are indicative of liquid surface water. Either climatic conditions were more favorable when these valley networks were forming, or some other mechanism was involved. One alternative is the possibility that the valley networks formed under a thick ice sheet, which may have created the necessary conditions for liquid water [Clifford and Parker, 2001]. In such a case, the networks would be discontinuous with large undissected interfluves and there would be no channels on the valley floors [Menzies and Shilts, 1996]. In parallel, no features were observed such as amphitheater heads of valley networks or collapse features typical of groundwater circulation and sapping processes [Laity and Malin, 1985; Malin and Carr, 1999]. In general the valley networks in Melas Chasma are characteristic of valleys formed by precipitations and surface runoff.

\subsection{Duration and Time of the Valley Networks and Paleolake}

[46] The high order of tributaries and the deep incision of the valleys attest to the maturity of the networks. Similar maturity on Earth is reached after several thousand years [Leopold et al., 1995]. The presence of sedimentary systems such as fans, fluvial features or lacustrine layers, attests to persistent flow. Such observations imply that at least locally, a water cycle involving atmospheric precipitation existed during over minimum of several thousand years.

[47] The Hesperian age of Valles Marineris ILDs [Head et al., 2001] suggests the maximum age of the networks is Hesperian (<3.6 Gy [Hartmann and Neukum, 2001]). The crater counts in our study agree with this age. Such an age is relatively young compared to the other studied valley networks, and it may explain why the morphology is so well preserved, as is illustrated by the preservation of the inner channels. Other Martian features suggesting warm and wet conditions are observed primarily before the late Hesperian [Craddock and Howard, 2002] which suggests that a warm and wet Early Mars climate transitioned into current climate conditions between the Early and the Late Hesperian. 


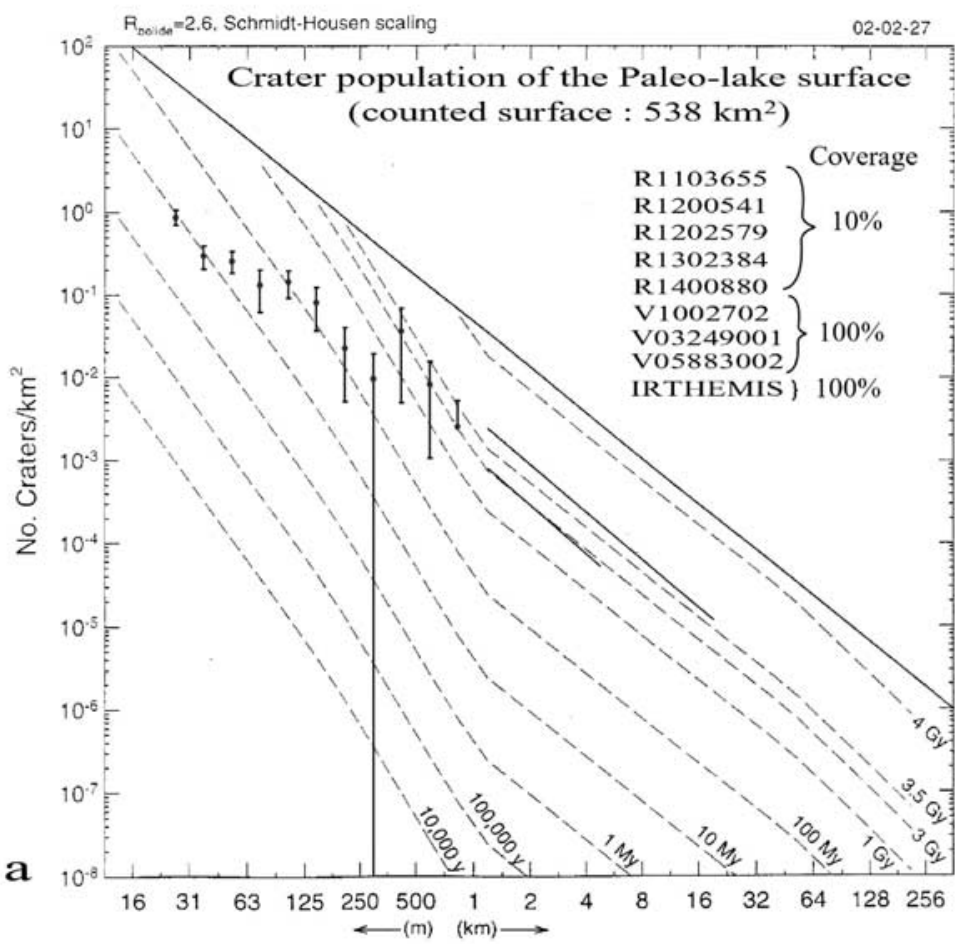

Diameter

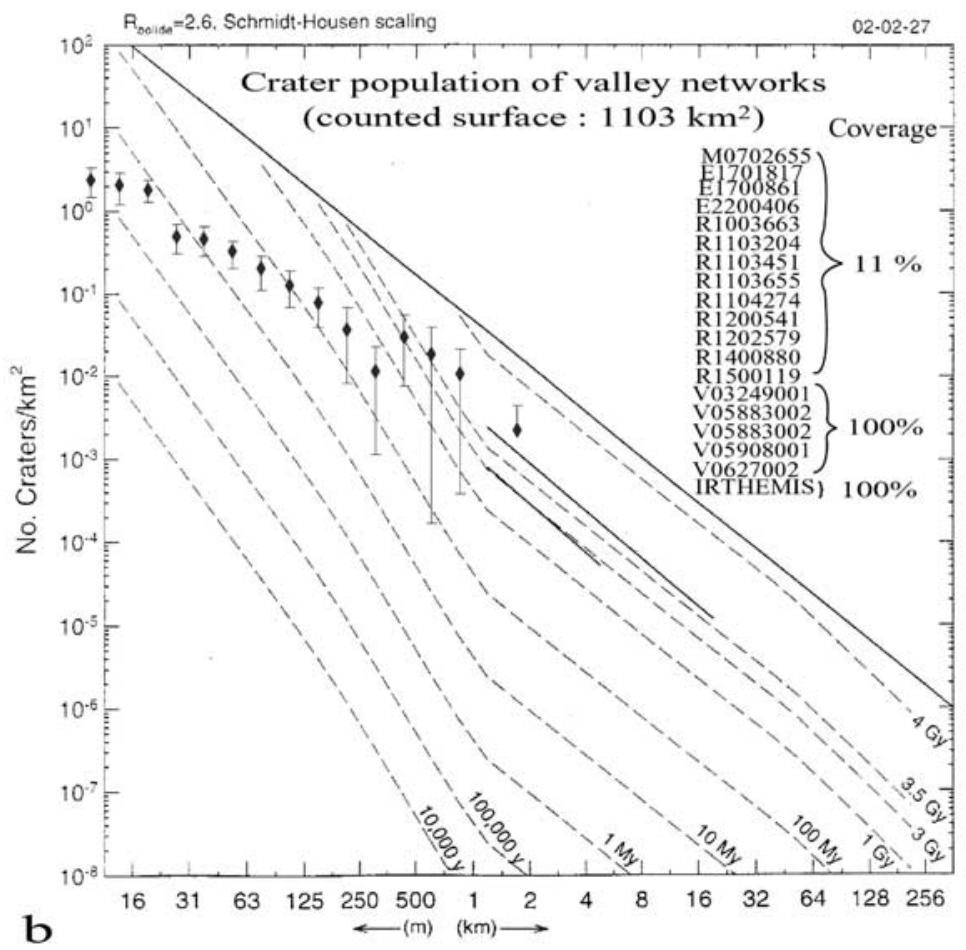

Diameter

Figure 13. Crater densities of the surfaces studied here. (a) Crater size distribution of the surface of the paleolake. (b) Crater size distribution of the surface of both valley networks studied here. The crater distribution indicates a complex history. 


\subsection{Sporadic Distribution of Valley Networks in Valles Marineris Area}

[48] Valley networks that date from the Late Hesperian are observed at other regions of Valles Marineris area. The plateau surrounding Valles Marineris has also been incised by dense, dendritic valley networks as found on both sides of Echus Chasma [Mangold et al., 2004]. Other remnant valley networks, not as well preserved as the Echus or Melas valley networks, are also observed around and within Juventea Chasma and within Ius Chasma. However, these observations are sporadic spatially within late Hesperian Valles Marineris material. Several possibilities may explain this sporadic distribution.

[49] Melas Chasma and Echus Chasma valley networks were observed by infrared images, which allow material with different thermal properties to be discriminated [Mangold et al., 2004]. The contrast between the dust filling the valley floor and the outcropping material reveals the valley networks. The depth of the valleys in Melas reaches $200 \mathrm{~m}$ (measured with MOLA data), which is ample relief to be eroded or covered, particularly if eolian processes were active for 3.5 Gy. Perhaps valley networks are observed in area that are partially covered or pristine.

[50] Melas Chasma valley networks are located on substratum different from the putative lava flows that form Valles Marineris wallslopes. Typically, no valley networks are observed on this material. Additionally, valley networks appear to form on a remnant of layered deposits. Precipitation could have occurred on both units, but the valleys only incised layered deposits and not the more resistant lavas flows. The presence of some valley heads just at the base of the wallslopes in Melas indicates the presence of a water reservoir within the wallslope material that could have been filled by infiltration from the surface surrounding Valles Marineris. In summary, the spatial distribution of the Late Hesperian valley networks in Valles Marineris region could be explained by the heterogeneity of the geological units or by the heterogeneity of eolian processes, or perhaps a combination of both.

\subsection{Implications for Valles Marineris Climate History}

[51] The formation of Valles Marineris occurred during the Hesperian period [Scott and Tanaka, 1986; Lucchitta et al., 1992] under climatic conditions assumed to be cold and dry. However, some studies suggest standing body of water within Valles Marineris which may be necessary to form the ILD [McCauley et al., 1978; Nedell et al., 1987; Komatsu et al., 1993; Lucchitta et al., 1994]. To reconcile the formation of ILD in a cold dry climate, some studies suggest that standing body of water was covered by ice [Chapman and Tanaka, 2001; Komatsu et al., 2004]. The subsequent erosion of the ILD by eolian or fluvial processes has also been discussed [Nedell et al., 1987; Komatsu et al., 1993]. Our observations attest that conditions during or after the erosion of the ILD were warm and wet in at least intervals persisting over several thousand years. These observations reinforce the possibility of wet and warm conditions during the formation of the ILDs. This is consistent with some previous studies of Valles Marineris which conclude to an early stage of wet and warm conditions [Lucchitta et al., 1994; Peulvast et al., 2001]. The study of Peulvast et al. [2001] suggests an early wet and warm climate in Valles
Marineris based on the style of erosion seen in the wallslopes of Valles Marineris. In particular, wallslopes show spur and gully morphology which is often associated with landscape modification from precipitation and surface runoff, whereas the scarps of the younger landslides are smooth. Landslides occur from 3 Gy to 50 my and postdate the large standing body of water in Valles Marineris [Quantin et al., 2004]. The climatic history of Valles Marineris could be divided into two periods. At the beginning of Valles Marineris, the canyon system could have experienced periodic wet and warm conditions leading to the formation of the ILDs and their subsequent erosion. Following this, the conditions would have been dry and cold as they are currently.

\subsection{Implications for the Martian Past Climate}

[52] The need for atmospheric precipitation constrains the climatic conditions at time of valley network formation. Precipitation implies that the temperature, pressure and water content in the atmosphere were higher than the present conditions. Either such warm, wet conditions correspond to a global climate that was sustained for a long period or they attest to episodic climatic conditions favorable to liquid water. Traditionally, it has been assumed that the transition between early climate conditions and current one occurred sometime between the Early and the Late Hesperian periods. The age of valley networks in Valles Marineris suggests that this transition occurred toward the end of the Hesperian.

[53] It has been demonstrated that liquid water could be stable for brief periods of time at certain locations in spite of cold and dry global climate due to such effects as orbital variations [Toon et al., 1980; Haberle, 1998]. The obliquity of Mars is strongly chaotic and can be modeled over the last million years only. However, the probability that the obliquity of Mars has reached more than $60^{\circ}$ in the last $3 \mathrm{~Gy}$ is 89.3\% [Laskar et al., 2004]. So, high obliquity epochs could have occurred during the middle history of Mars. At high obliquity, the polar cap becomes unstable and releases $\mathrm{CO}_{2}$ and $\mathrm{H}_{2} \mathrm{O}$ into the atmosphere [Jakosky et al., 1995]. Recent GCM simulations report that at high obliquity the polar cap ice is redistributed toward equatorial latitudes [Levrard et al., 2004]. This could possibly account for precipitation in the equatorial regions. However, processes due to orbital variations are cyclic and are certainly still active, whereas the fluvial activity in Melas is dated at the beginning of Valles Marineris history. Moreover, the $\mathrm{CO}_{2}$ released from the polar caps would not be sufficient enough to create an effective greenhouse effect.

[54] There are other possible mechanisms for creating a periodic warm, wet climate. Segura et al. [2002] reported that impact events with diameter of $250 \mathrm{~km}$ may be able to warm the surface of Mars by liberating groundwater from the impactor and from the target material (assuming a waterrich Martian regolith). Those conditions could produce up 2 meters to rain annually. However, such conditions decrease quickly and in $\sim 5$ years the climate returns to the pre-impact conditions. Such a scenario is not consistent with the observed maturity of Melas Chasma valley networks. Moreover, the probability of such an impact with the necessary dimensions is one impact per 3.5 Gy in the $1.10^{7} \mathrm{~km}^{2}$ composing Valles Marineris area. 
[55] Another possibility is gas released from large-scale volcanism. Potentially gases released from volcanism could lead to a global climatic change [Baker, 1991; Polack et al., 1987]. During intervals in Martian history, enough gas may have been released to create conditions favorable for liquid water. Such processes have also been suggested to explain the formation of the outflows channels [Baker, 1991]. The fluvial activity of Melas Chasma is contemporaneous to the activity of some outflow channel formation from Valles Marineris [Scott and Tanaka, 1986] and could correspond to the same climatic event. In this hypothesis, it is difficult to determine if wet and warm climatic conditions would be the cause of the activity of the outflow channels or if the climatic conditions would be the consequence of the outflow channels. Indeed, outflow channel activity could have been triggered by mantle plume activity leading to an intense volcanic phase [Baker, 1991, 2001]. Such mechanisms might be able to modify the climatic conditions. On the other hand, the cataclysmic floods of the outflow channels may also have induced a water cycle lasting several thousand years [Baker, 2001]. All these hypotheses have to be tested in the GCM simulation of the Martian past climate integrating a water cycle.

\subsection{Implications for Astrobiology}

[56] The evidence of a past body of standing water during the Late Hesperian is of high relevance to objectives in astrobiology. To date, the data accumulated by the landers failed to provide convincing evidence for the presence of an extant biota on Mars [Klein et al., 1976; Levin and Straat, 1976]. Instead, several different experiments conducted on samples of the Martian regolith strongly suggested the presence of oxidants in the surface material [e.g., Soffen, 1976; Golombek et al., 1997]. These observations, together with extremely arid conditions, would appear to preclude the existence of indigenous organisms. However, since liquid water is a requirement for life, a temporary lake is an adequate environmental niche wherein microbial existence might have occurred. This feature has been inferred to have developed after $3.5 \mathrm{~Gy}$, that is coincident in time with the oldest identified living forms on Earth, namely microfossils and stromatolites found in 3.5 to 3.3 Gyr-old sediments from South Africa and Western Australia [Schopf and Walter, 1983].

\section{Conclusion}

[57] Melas Chasma contains valley networks that have high drainage density attesting to their maturity. Analyses of these valleys reveal inner channels on some floors indicating that liquid water flowed within these valleys and eroded them. The density, organization and maturity of valley networks suggest that the network has been originated by precipitation. The topography indicates that the valley networks flow into an enclosed depression. The geometrical features and the morphology of this depression suggest that a paleolake developed in relation with the activity of the valley networks. The system probably lasted several thousand years in order to erode the valley networks and form the fans. These landforms are located on remnant layered deposits possibly containing sulfates suggesting that liquid water played a role in eroding and isolating the layered deposits of Valles Marineris. Collectively, the features in Melas Chasma date to the Late Hesperian period, demonstrating that an efficient water cycle existed after $3.5 \mathrm{~Gy}$ in Valles Marineris with atmospheric precipitations driving a fluvio-lacustrine system. These results suggest that the Hesperian period was at least wet and warm episodically, extending the interval of time such conditions were previously thought to have occurred on Mars. The evidence for a paleolake in Melas Chasma attests to adequate environmental conditions for life development through the Hesperian period.

[58] Acknowledgments. We thank Malin Space Science Systems for the availability of the MOC images on the Web site http://www.msss.com/ moc gallery/ and THEMIS teams for the availability of the data on the Web site http://themis-data.asu.edu/. We gratefully acknowledge B. Lucchitta and B. Craddock for valuable and constructive reviews of this paper. They also greatly improved the final English of this paper. This work was supported by the PNP (Programme National de Planetologie) of INSU (Institut National des Sciences de l'Univers) from France. We appreciated the valuable conversations with $\mathrm{H}$. Pigay, B. Levrard, and Mary Bourke.

\section{References}

Aharonson, O., D. E. Zuber, D. H. Rothman, N. Schorghofer, and K. X. Whipple (2002), Drainage basins and channel incisions in Mars, Proc. Natl. Acad. Sci. U. S. A., 99, 1780-1783.

Baker, V. R. (1991), Ancient ocean, ice sheets and the hydrological cycle on Mars, Nature, 352, 589-594.

Baker, V. R. (2001), Water and the Martian landscape, Nature, 412, $228-$ 236.

Carr, M. (1995), The Martian drainage system and the origin of valley networks and fretted channels, J. Geophys. Res., 100, 7479-7507.

Carr, M. (1999), Retention of an atmosphere on Early Mars, J. Geophys. Res., 104, 21,897-21,909.

Carr, M., and F. C. Chuang (1997), Martian drainage densities, J. Geophys. Res., 102, 9145-9152.

Carr, M., and M. Malin (2000), Meter-scale characteristics of Martian channels and valleys, Icarus, 146, 366-386.

Chapman, M. G., and K. L. Tanaka (2001), Interior trough deposits on Mars: Subice volcanoes?, J. Geophys. Res., 106(E5), 10,087-10,100.

Christensen, P. R., et al. (2003), Morphology and composition of the surface of Mars: Mars Odyssey THEMIS results, Science, 300, 2056-2062

Clifford, S. M., and T. J. Parker (2001), Evolution of the Martian hydrosphere, Icarus, 154, 40-79.

Clow, G. D. (1987), Generation of liquid water through the melting of a dusty snowpack, Icarus, 72, 95-127.

Craddock, R. A., and A. D. Howard (2002), The case for rainfall on a warm, wet early Mars, J. Geophys. Res., 107(E11), 5111, doi:10.1029/ 2001JE001505.

Craddock, R. A., and T. Maxwell (1993), Geomorphic evolution of Martian highlands through ancient fluvial processes, J. Geophys. Res., 98, 34533468 .

Dohm, J. M., and K. L. Tanaka (1999), Geology of the Thaumasia region, Mars, Planet. Space Sci., 47, 411-431.

Gendrin, A., et al. (2005), Sulfates in Martian layered terrains: The OMEGA/Mars Express view, Science, 307, 1587-1591.

Girardclos, S. (2001), Sismostratigraphie et structure sédimentaire en 3 D d'un basin lacustre, du retrait glaciaire à nos jours (Lac Leman, Suisse), 196 pp., Institut Forel, Fac. des Sci. de l'Univ. de Genève, Geneva.

Golombek, M. P., et al. (1997), Overview of the Mars Pathfinder Mission and assessment of landing site predictions, Science, 278, 1743-1748.

Haberle, R. M. (1998), Early Mars climate models, J. Geophys. Res., 103, $28,467-28,479$.

Hartmann, W. K. (1999), Martian cratering VI: Crater count isochrons and evidence for recent volcanism from Mars Global Surveyor, Meteorit. Planet. Sci., 34, 167-177.

Hartmann, W. K., and G. Neukum (2001), Cratering chronology and the evolution of Mars, Space Sci. Rev., 96, 165-194

Head, J. W., R. Greeley, M. P. Golombek, W. K. Hartmann, E. Hauber, R. Jaumann, P. Masson, L. E. Nyquist, and M. H. Carr (2001), Geological processes and evolution, Space Sci. Rev., 96, 263-292.

Horton, R. E. (1945), Erosional development of streams and their drainage basins: Hydrophysical approach for quantitative morphology, Geol. Soc. Am. Bull., 82, 1355-1376. 
Jakosky, B. M., B. G. Henderson, and M. T. Mellon (1995), Chaotic obliquity and the nature of the Martian climate, J. Geophys. Res., 100, $1579-1584$.

Klein, H. P., et al. (1976), The Viking biological investigation: Preliminary results, Science, 194, 99-105.

Komatsu, G., P. E. Geissler, R. G. Strom, and R. B. Singer (1993), Stratigraphy and erosional landforms of layered deposits in Valles Marineris, J. Geophys. Res., 98, 11,105-11,121.

Komatsu, G., G. Ori, P. Ciarcelluti, and Y. D. Litasiv (2004), Interior layered deposits of Valles Marineris, Mars: Analogous subice volcanism related to Baikal Rifting, southern Siberia, Planet. Space Sci., 52, 167187.

Laity, J. E., and M. Malin (1985), Sapping processes and the development of theater-headed valley networks on the Colorado plateau, Geol. Soc. Am. Bull., 96, 203-217.

Laskar, J., A. C. M. Correia, M. Gastineau, F. Joutel, B. Levrard, and P. Robutel (2004), Long term evolution and chaotic diffusion of the insolation quantities of Mars, Icarus, 170, 343-364.

Leeder, M. R. (1999), Sedimentology and Sedimentary Basins, Blackwell Sci., Malden, Mass.

Leopold, L., M. G. Wolman, and J. Miller (1995), Fluvial Processes in Geomorphology, Dover, Mineola, N. Y.

Levin, G. V., and P. A. Straat (1976), Viking labeled release biology experiment: Interim results, Science, 194, 1322-1329.

Levrard, B., F. Forget, F. Montmessin, and J. Laskar (2004), Recent ice-rich deposits formed at high latitude on Mars by sublimation of unstable equatorial ice during low obliquity, Nature, 431, 1072-1075.

Lucchitta, B. K., A. McEwen, G. D. Clow, P. E. Geissler, R. B. Singer, R. A. Schultz, and S. W. Squyres (1992), The canyon system on Mars, in Mars, edited by H. H. Keiffer et al., pp. 453-492, Univ. of Ariz. Press, Tucson.

Lucchitta, B. K., N. K. Isbell, and A. Howington (1994), Topography of Valles Marineris: Implications for erosional and structural history, J. Geophys. Res., 99, 3783-3798.

Malin, M., and M. Carr (1999), Groundwater formation of Martian valleys, Nature, 197, 589-591.

Malin, M. C., and K. S. Edgett (2000), Sedimentary rocks of Early Mars, Science, 290, 1927-1937.

Mangold, N., C. Quantin, V. Ansan, C. Delacourt, and P. Allemand (2004), Evidence for precipitation on Mars from dendritic valleys in the Valles Marineris area, Science, 305, 78-81.

Masursky, H. J. (1973), An overview of geologic results of Mariner 9 J. Geophys. Res., 78, 4009-4030.

Masursky, H., M. Boyce, A. L. Dial, G. G. Schaber, and M. E. Strobell (1977), Classification and time of formation of Martian channels based on Viking data, J. Geophys. Res., 82, 4016-4038.

McCauley, J. F., M. Carr, J. A. Cutts, W. K. Hartmann, H. Masursky, D. J. Milton, R. P. Sharp, and D. E. Wilhelms (1978), Preliminary Mariner 9 report on the geology of Mars, Icarus, 17, 289-327.

McCauley, J. F., G. G. Schaber, C. S. Breed, M. J. Grolier, C. V. Haynes, B. Issawi, C. Elachi, and R. Blom (1982), Subsurface valleys and geoarcheology of the eastern Sahara revealed by shuttle radar, Science, 218, 1004-1020.

McEwen, A. S., M. C. Malin, M. H. Carr, and W. K. Hartmann (1999), Voluminous volcanism on early Mars revealed in Valles Marineris, Nature, 397, 584-586.
Menzies, J., and W. W. Shilts (1996), Subglacial environments, in Past Glacial Environments, edited by J. Menzies, pp. 15-136, Elsevier, New York

Nedell, S. S., S. W. Squyres, and D. W. Andersen (1987), Origin and evolution of the layered deposits in the Valles Marineris, Mars, Icarus, 70, 409-441.

Pelkey, S. M., and B. M. Jakosky (2002), Surficial geological surveys of Gale Crater and Melas Chasma, Mars: Integration of remote-sensing data, Icarus, 160, 228-257.

Pelkey, S. M., B. M. Jakosky, and P. R. Christensen (2003), Surficial properties in Melas Chasma, Mars, from Mars Odyssey THEMIS data, Icarus, 165, 68-89.

Peulvast, J. P., D. Mège, J. Chiciak, F. Costard, and P. L. Masson (2001), Morphology, evolution and tectonics of Valles Marineris wallslopes (Mars), Geomorphology, 37, 329-352.

Phillips, L. F., and S. A. Schumm (1987), Effect of regional slope on drainage networks, Geology, 15, 813-816.

Pollack, J. B., J. F. Kasting, S. M. Richardson, and K. Poliakoff (1987), The case of a wet and warm climate on early Mars, Icarus, 71, 203-224.

Quantin, C., P. Allemand, N. Mangold, and C. Delacourt (2004), Ages of Valles Marineris (Mars) landslides and implications for canyon history, Icarus, $172,555-572$.

Schopf, J. W., and W. R. Walter (1983), Archean microfossils: New evidence of ancient microbes, in Earth's Earliest Biosphere: Its Origin and Evolution, edited by J. W. Schopf, pp. 214-239, Princeton Univ. Press, Princeton, N. J.

Scott, D. H., and K. L. Tanaka (1986), Geologic map of the western equatorial region of Mars, U.S. Geol. Surv. Misc. Invest. Map, I-1802-A.

Schumm, S. A. (1977), The Fluvial System, 338 pp., John Wiley, Hoboken, N. J.

Segura, T. L., O. B. Toon, A. Colaprete, and K. Zahnle (2002), Environmental effects of large impacts on Mars, Science, 298, 1977-1980.

Soffen, G. A. (1976), Scientific results of the Viking missions, Science, $194,1274-1276$.

Squyres, S., and J. F. Kasting (1994), Early Mars: How warm and how wet?, Science, 265, 744-749.

Stanistreet, I. G., and T. S. McCarthy (1993), The Okavango fan and the classification of subaerial fan systems, Sediment. Geol., 85, 115-133.

Stepinski, T. F., M. L. Collier, P. J. McGovern, and S. M. Clifford (2004), Martian geomorphology from fractal analysis of drainage networks, J. Geophys. Res., 109, E02005, doi:10.1029/2003JE002098.

Toon, O. B., J. B. Pollack, A. W. Ward, J. A. Burns, and K. Bilski (1980), The astronomical theory of climate change on Mars, Icarus, 44, 552607

Weitz, C. M., T. J. Parker, M. H. Bulmer, F. Scott Anderson, and J. A. Grant (2003), Geology of the Melas Chasma landing site for the Mars Exploration Rover mission, J. Geophys. Res., 108(E12), 8082, doi:10.1029/ 2002JE002022.

P. Allemand, C. Delacourt, G. Dromart, and C. Quantin, Laboratoire Sciences de la Terre, UMR 5570, CNRS Université Claude Bernard Lyon1, ENS Lyon, Bat Géode, 6 ${ }^{\mathrm{e}}$ Etage, 2 Rue Raphaël Dubois, F-69622 Villeurbanne Cedex, France. (cathy.quantin@univ-lyon1.fr)

N. Mangold, OrsayTerre, Bat. 509, Université Paris-Sud, F-91405 Orsay Cedex, France. 